\title{
Accessibility patterns: Northern Italy Case Study ${ }^{1}$
}

\author{
Davide Fiorello, Dorota Bielańska \\ TRT Trasporti e Territorio SRL \\ Via Rutilia, 10/8 20141, Milan, Italy \\ fiorello@trt.it,dorota@trt.it
}

\begin{abstract}
This paper looks into the municipal dimension of accessibility of Northern Italy macro-region using the analytical framework developed under the TRACC project. Northern Italy is a quite densely populated region whose dominant spatial feature is the so called 'enlarged city', but at the same time nearly half of its territory is classified as 'mountains'.

The overall picture is one of a region with high levels of local accessibility. Two thirds of the population can reach more than 1 million jobs in less than one hour by car. At the same time, almost $90 \%$ of inhabitants do not need more than 20 minutes to reach the closest hospital and more than half can get to the nearest regional centre in 30 minutes or less using public transport.

Nevertheless, some disadvantaged areas exist. Transport infrastructures play some role in explaining the differences in accessibility, even though they are not the major driver. Indeed, the most disadvantaged LAU2 zones suffer due to their peripheral (and often mountainous) condition rather than the lack of roads or transport services.

Planned trans-European transport networks would significantly change the accessibility pattern only on a local scale, whereas the overall pattern in the study region is not changed that much.
\end{abstract}

Keywords: accessibility, transport infrastructure, accessibility pattern, TEN-T, GIS, Northern Italy.

\section{Case study introduction}

The case study area covers Northern Italy, including the following administrative regions (also NUTS 2 regions): Valle d'Aosta, Piemonte, Liguria, Lombardia, Veneto, Trentino Alto Adige, Friuli Venezia Giulia and Emilia Romagna. The surface area is around 120,000 $\mathrm{km}^{2}$ (Figure 1).

From the north, the macro region is bordered by the Alps, which form a natural border with the neighbouring countries (France, Switzerland, Austria and Slovenia). This barrier is, however, crossed by several natural or artificial passages (like the Frejus tunnel, the Simplon tunnel and the Brenner

1 This paper has been developed under the applied research project TRansport ACCessibility at regional/local scale and patterns in Europe led by Spiekermann \& Wegener Urban and Regional Research (S\&W) Germany. It has been financed by the ESPON 2013 Programme and its financial support is gratefully acknowledged. Texts, maps and conclusions stemming from research projects under the ESPON programme presented in this paper do not necessarily reflect the opinions of the ESPON Monitoring Committee. C ESPON, 2013. 
tunnel) that connect Northern Italy with Western and Central Europe by road and rail. Improvements to north-south corridors are being implemented (the new rail Gotthard basis tunnel) or are planned (the new rail Brenner tunnel), even with no corresponding investments in Italy. Neighbouring regions of France, Switzerland, Austria and Slovenia can be reached also through a number of smaller customs crossing the borders.

The south border of the study area is just an administrative division, especially on the southeastern side with clear territorial continuity with other regions. On the south-western side of the study area, the Apennines form a physical barrier but both road and rail connections are well-established and have been further improved after the opening of the high speed rail track in 2009.

The physical and political borders do not prevent mobility between the case study regions and the neighbouring regions. At the same time, for the administrative, economic and social function considered below to analyse the levels of accessibility in the area, these borders are significant divisions which basically "insulate" the case study regions. As a matter of fact, schools and medical services are provided by national authorities, therefore the political border in the northern side of the area is a real barrier. The same applies to jobs, even if a minority of the inhabitants of border zones are employed in the neighbouring countries (especially Switzerland). At the same time, the Apennines represent a natural separation and basically all the inhabitants at the south-western side of the study region are bound to functions available within the region, as services and jobs located in the southern side of the Apennines are too far away. The only part of the study area where permeability with external regions can exist is the extreme south-eastern side. In summary, the Northern Italy region can serve as a case study for accessibility analysis quite well as border effects are very limited.

\section{Spatial structure}

Even as $46 \%$ of the territory of Northern Italy is classified as 'mountains', the average population density is 230 people per $\mathrm{km}^{2}$, above the national average of 200 people per $\mathrm{km}^{2}$. The dominant spatial feature of Northern Italy is the 'enlarged city'. Especially in the northern part of the area just below the Alps, on the west-east axis between Turin and Venice, urbanisation is virtually continuous and forms what has been called the 'Padan megalopolis' (Turri, 2004). Another 'enlarged city' can be identified in the southern part of the area, on the Turin-Bologna axis. In between, urbanisation is less predominant and several medium-sized cities (with a population from 20,000 to 50,000) characterise a more polycentric structure. The 'enlarged city' model is reflected in the absence of a dominant centre. Milan is the largest city in the area with a population of about 1.3 million (i.e. less than $5 \%$ of the overall population in macro region). Other large cities are Turin ( 0.9 million population), Genoa ( 0.6 million) and Bologna ( 0.38 million). This means that the four major cities of the area account for just a bit more than $10 \%$ of the overall population of the region. The majority of the population live in the 'enlarged city' made of a number of small municipalities, many of which are separate entities only from the administrative point of view.

\section{Socio-economic situation}

Northern Italy is the richest and most populated area of the country. About 27 million people live in the case study region, i.e. nearly a half of the entire Italian population. Also, about $60 \%$ of the national Gross Domestic Product is generated in this area. The industry structure mainly consists of a number of small or family-run companies spread all over the territory. Therefore, also jobs are highly distributed across the study area (with the exception of the mountains). Even though the most populated centres also concentrate many jobs, the jobs to population rate is not higher than in small 
villages. There are several 'districts' specialised in specific production types (e.g. silk, glasses, ceramics, shoes). Nevertheless, industrial production has been decreasing from the 1970s making room for the development of services and tertiary activities. Milan is the major economic centre in Italy. Formerly an industrial area, it is now a service and financial centre, the site of the Italian stock exchange and of most of Italian offices of international companies, as well as one of world's fashion capitals.

The contribution of births to population development is almost null and in the recent years the population has slightly increased only because of immigration from Southern Italy and from abroad. In the agricultural and industrial sectors, immigrants (especially from Eastern Europe, North and Central Africa) represent a significant share of manpower (despite official statistics lacking).

\section{Transport aspects}

Transport infrastructures and services are generally well developed in Northern Italy. However, high population density coupled with the 'enlarged city' form of urbanisation and the economic structure made of many small companies generate a large amount of transport demand that gives rise to congestion problems.

The major road infrastructures are the west-east A4 and the A1 north-south motorways, but on both axes also other motorways exist. Nevertheless, especially A4 has been often faced with severe congestion problems. Recently, the newly opened fourth lane between Brescia and Milan has relieved traffic. Furthermore, new infrastructures started to be built between 2009 and 2010, namely the 'Brebemi' motorway, linking the city of Milan with Brescia via Bergamo, and the 'Pedemontana' motorway, connecting the A4 motorway from Dalmine with the Malpensa airport, crossing the provinces of Lecco, Monza and Como. Other motorway projects are still in a more or less advanced planning phase.

Besides motorways, an extensive network of national and regional roads connects all parts of the macro-regions. Also mountain areas are generally very well connected since many of them are tourist resorts, particularly popular in winter time.

Railways in the macro-region are highly developed around the Milan node, but most of the municipalities in the area (at least those not located in the mountains) are reasonably close to railways. However, infrastructures have basically been developed in the first half of the 20th century (indeed, some railway lines existing until mid-1960s have been abandoned so that total railway length is today a bit shorter than 50 years ago). Railways were built to connect main cities with each other and to connect medium centres with the main poles (especially Milan and Turin) developing according to a radial model. The development of the population and activities scattered throughout the area have seriously disadvantaged railways, which are more suitable for carrying large volumes of passengers (and freight) over fixed paths. Furthermore, in the past ten or fifteen years Italian railways have chosen to develop the high speed network rather than local services. The outcome has been that such services suffer underinvestment of the rolling stock and infrastructure update. They are overcrowded during peak time and infamous for their unreliability (delays). All in all, despite a quite extended railway network, train services are well below the European standard. Only the recently inaugurated high speed line, connecting Milan with Rome in three hours, can be considered a quality service that has increased the connectivity of the area. 


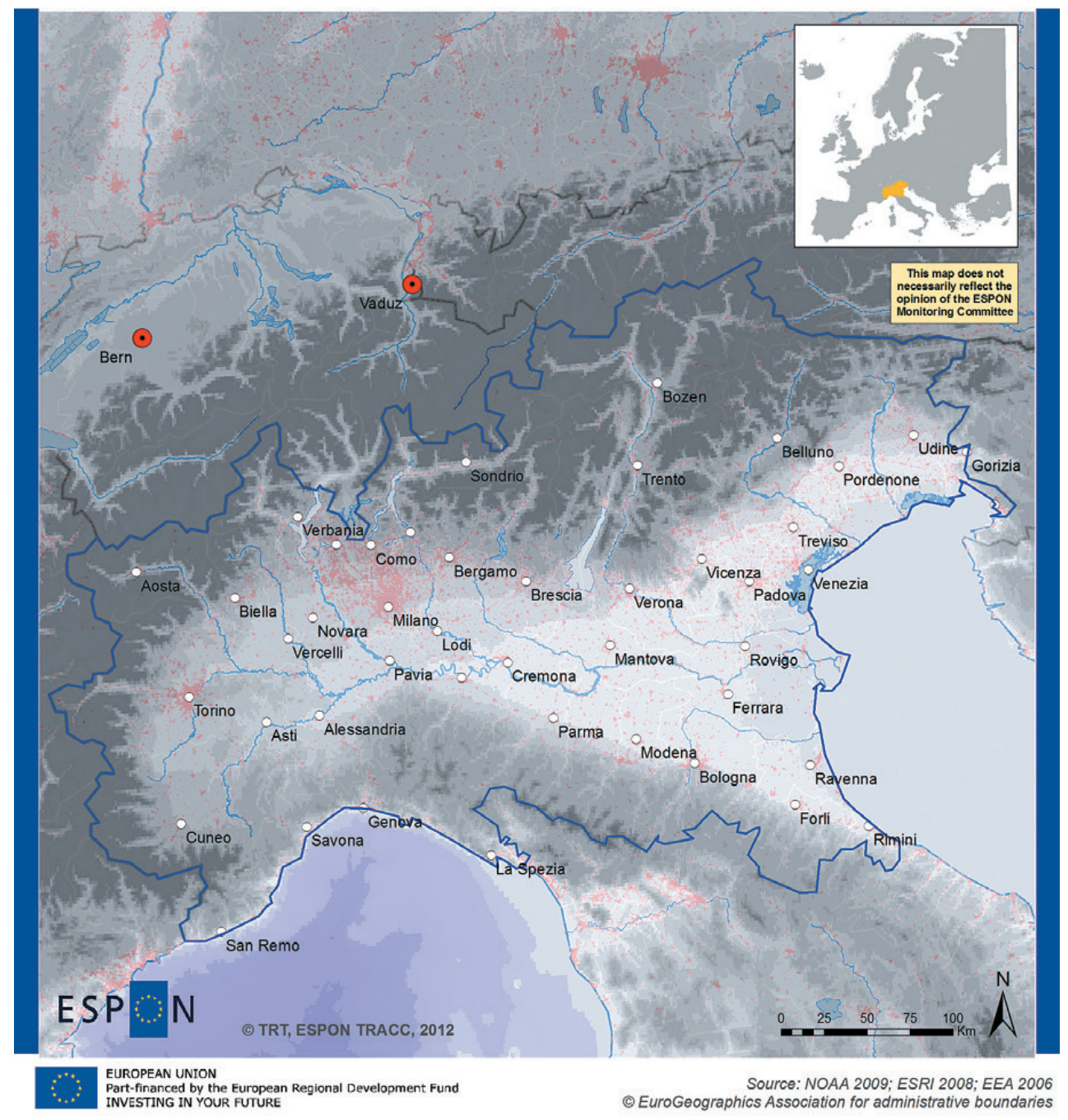

\section{Northern Italy Case Study \\ Physical map}

$\begin{array}{lll}\text { Settlement area } & \odot & \text { Capital city } \\ \text { Rivers } & \circ & \text { NUTS3 Capital } \\ \text { Lakes } & & \end{array}$

Figure 1. Northern Italy case study region. 


\section{Accessibility patterns}

In this section, an analysis of accessibility in the Northern Italy region is presented. The analysis concerns accessibility for car and for public transport. The latter includes (interurban) public bus and coach services as well as train services (high-speed train and regional train services). For all elements not explicitly mentioned below, the methodology used for the analysis is the one common for all the case studies described in the introductory chapter (Biosca et al., 2013).

The accessibility model used to calculate travel times and costs for the accessibility indicators is a network model developed by TRT in the MEPLAN software environment. The model allows the assignment of Origin-Destination matrices at the LAU2 level of detail for both road and rail.

The networks represented in the model come from different sources. The rail layer is taken from the RRG GIS Database (RRG GIS Database, 2011), whereas the road layer derives from the one of OpenStreetMaps (Open Street Map, 2011). While all railway links that operate today for passenger transport in the macro-region are included (freight only lines are excluded), only a subset of the entire road network as provided by OpenStreetMap (OSM) has been selected. Namely, the subset covers all motorways and expressways, as well as dual-carriageway roads, plus other trunk roads, secondary roads or tertiary roads, to guarantee connectivity of all municipalities.

Accessibility indicators depend on travel cost and time. For public transport, costs are based on Trenitalia (the major rail operator in Italy) data on tariffs (TRENITALIA, 2011) and on a sample of bus service fares in Northern Italy. Travel times are results of the assignment made using the transport network model. Public road transport is not simulated based on actual timetables because bus and coach services in Northern Italy are provided by a large number of local operators, due to which collecting and implementing the actual timetables in the network model was not feasible. Bus travel times on $\mathrm{O} / \mathrm{D}$ pair has been obtained by means of assignment with reduced speed on road links. The level of reduction has been defined by comparing modelling results to actual travel times according to timetables for a sample origin-destination pairs. The use of rail or bus as public transport for a given origin-destination pair is an endogenous modelling result based on availability and competitiveness in terms of travel time. In particular for $\mathrm{O} / \mathrm{D}$ pair $<70 \mathrm{~km}$, the minimum time between rail and road has been selected. For O/D pair $>70 \mathrm{~km}$, road public transport is basically non-existent.

Results regarding some of the indicators are presented below. A wider range of accessibility indicators can be consulted in the Regional Case Study Book of the TRACC Final Report (Fiorello and Bielanska, 2013).

\section{Daily accessibility of jobs by car}

This indicator makes reference to the number of jobs available with a driving time of one hour. The number of jobs within each LAU2 is taken from the 2001 activity census data published by the Italian statistical office (ISTAT, 2001).

As already mentioned, the Northern Italy area is rich in economic activity spreading over most of its territory, rather than concentrated in a few spots. As a result of this level of density, nearly a half of the zones and two-thirds of the population can reach more than 1 million jobs in less than one hour by car (Figure 2).

Not surprisingly, the difference of job accessibility between zone types is large. The median of the distribution for urban zones and other zones close to a city is several times larger than the median for remote areas which, however, are just a small share of the LAU2 in the Northern Italy 
area and cover even a smaller share of population. The inhabitants of these zones, mainly located in mountain areas, can reach less than 100,000 jobs within 60 minutes. In other words, the people who live in these areas have definitely less alternatives in terms of job availability, with tourism being the major workplace provider.

The density of activities as well as of the population, and therefore the accessibility of jobs, is especially high in the sub-region surrounding the metropolitan area of Milan. This sub-region spreads over different administrative districts. Its boundaries are defined by economic and geographical considerations, and the role of local authorities at the regional level is not recognisable. It is remarkable that areas around other traditional industrial centres like Turin and Genoa show an accessibility pattern which is definitely less favourable than in the area around Milan. This is mostly explained by the different density of activities in the LAU2 zones around the main cities, but the crisis of the automotive sector and other heavy industry sectors which have been traditionally located in cities like Turin and Genoa is also an influence.

\section{Regional accessibility potential by car}

Potential accessibility is calculated with respect to the population size. Data on the population are derived from the data published by the Italian statistical office (ISTAT, 2006).

The map of the potential accessibility by car to the population makes the "enlarged cities", which characterise the territory of the study area, quite visible. There is apparent continuity in the (above-average) level of potential accessibility throughout the Padan region and in the northern part of the corridor between Turin and Bologna (Figure 3). The average potential accessibility in the area does not result from very high values for a few zones and a large number of lower values. $20 \%$ of zones (accounting for more than one-third of population) exceed the average. This means that despite some polarisation there is relatively even distribution of potential accessibility in the core of the area. Of course, potential accessibility of very peripheral LAU2 areas is well below the average, but they account for only $6 \%$ of population.

Although population density is largely the most relevant driver of the potential accessibility pattern, the role of transport infrastructures is visible. The motorway network can be recognised especially along the corridor from Milan to Brescia passing through Bergamo and along the "via Emilia" from Milan to Bologna, but also in other corridors.

In general, the two indicators related to potential accessibility and to the accessibility of jobs display slightly different patterns. There are two reasons for this difference. One reason is that in the core of the region jobs are more evenly distributed than the population. This is especially true for the north-east triangle Milan-Venice-Bologna. The second reason is methodological, as the two indicators are not the same. Given the density in the core of the study area, computing the number of functions available within one hour provides a flatter picture than the indicator which detects whether the function is 15 minutes of 45 minutes away.

\section{Access to regional centres by public transport}

Given the definition adopted (NUTS 3 capitals plus cities with a population of more than 50,000 ), there are 60 regional centres distributed over the whole study area. The accessibility of such centres is generally good for most of the LAU2 units (Figure 4). The zones and population shares with travel time to the closest regional centre by public transport lower than 30 minutes are $23 \%$ and $57 \%$, respectively. Only $22 \%$ of the zones and $6 \%$ of the population need more than 60 minutes to reach a regional centre by bus or train. 
The map quite clearly shows that low public transport accessibility of the closest region centre is found in mountain areas at the borders but also, less frequently, in some portions of the study region where rail infrastructure is underdeveloped in comparison to the rest of the region. One instance is the area between the southern part of the NUTS 2 Veneto and the north-eastern part of the NUTS 2 Emilia Romagna, where for several LAU2 zones the travel time to the nearest centre is an hour or more.

Accessibility is especially good along the railway network. Indeed, in some cases train is even faster than car. This happens in the proximity of the major centres because of higher road congestion.

\section{Access to health care facilities by car}

The analysis of accessibility of health care facilities takes into account the number of hospitals resulting from the data of the Italian Ministry of Health (Italian Ministry of Health, 2010) and from Open Street Map layer (Open Street Map, 2011). In Italy, the public health care system has been dominant for the last decades. A dense network of public hospitals providing a wide range of services (including emergency services) has been one result of this model. Therefore, accessibility of hospitals by car in Northern Italy is rather good (Figure 5). $62 \%$ of zones and $89 \%$ of the population can reach the nearest hospital in less than 20 minutes, while $82 \%$ of zones and $97 \%$ of population need no more than 30 minutes. Only for $6 \%$ of zones, where less than $1 \%$ of the population lives, car travel time to the nearest hospital is longer than 40 minutes.

When comparing the map in Figure 5 with the previous accessibility maps, it is remarkable to see than many LAU2 zones, which are clearly disadvantaged for other indicators, are instead comparable for this indicator. Nevertheless, the map also reveals some spots where a few zones have clearly lower accessibility than neighbouring zones.

Quite even distribution of accessibility of hospitals is also proven by similar distributions of different types of zones. Yet urban areas are mostly distributed below (i.e. better than) the average, but the difference with rural regions is much more limited than for the other accessibility indicators mentioned above. The same conclusions can be drawn looking at the cumulate distributions of the population: better performance of urban zones in comparison with rural zones is confirmed, but the gap between different zones type is small.

It should be noted that in recent years some forms of privatisation have been introduced in the health care system and that plans for closing smaller hospitals have been periodically put forward (the latest one is a recent government project issued in early July 2012). If such plans were put into practice, the accessibility analysis presented here could change significantly. 


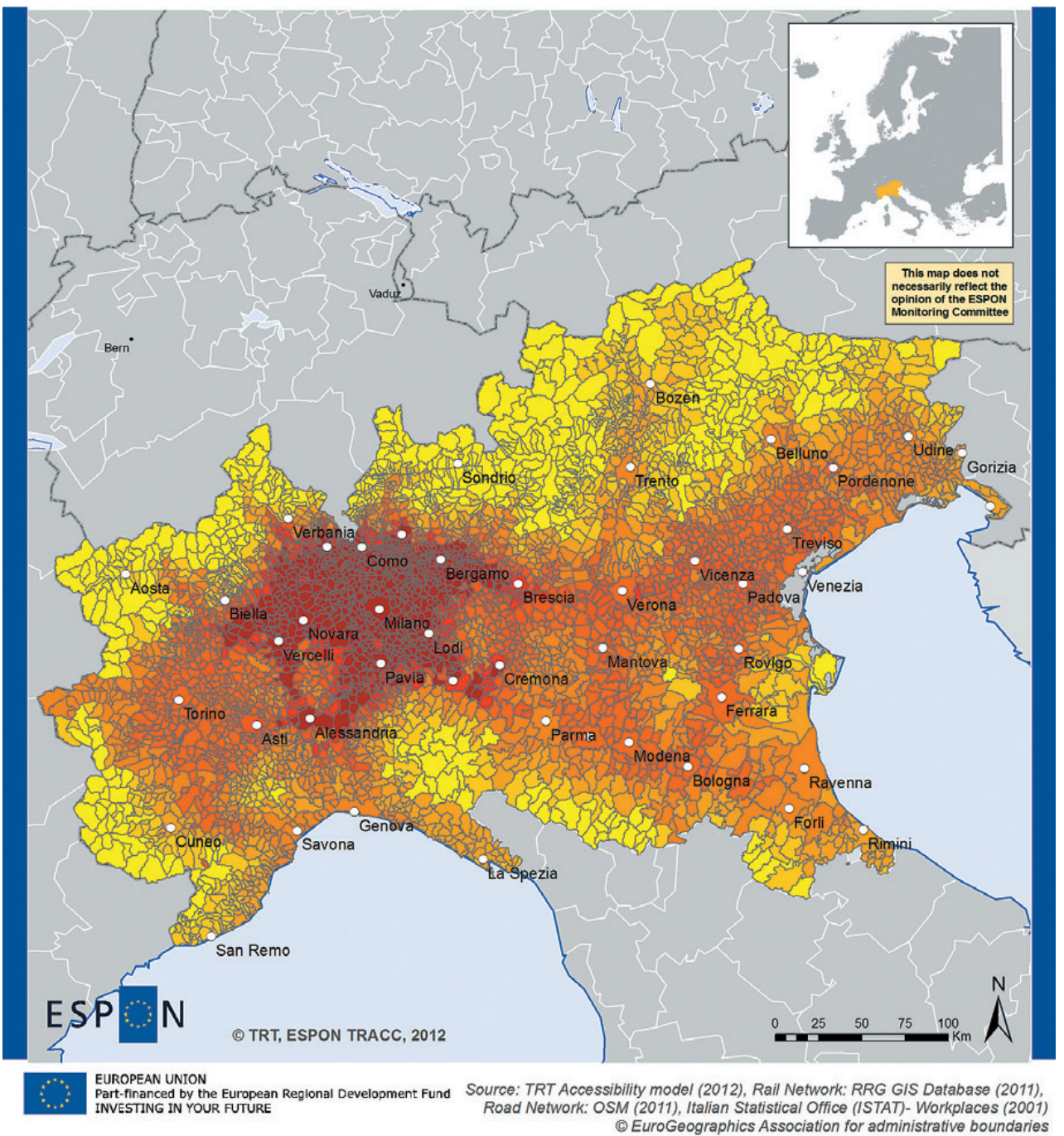

\section{Northern Italy Case Study (2011)}

Daily accessibility of jobs: Jobs (ths.) accessibile within 60 minutes by road
$0-100$
$101-250$
$251-500$
$501-1000$
$1001-1500$
$1501-2000$
$2001-2500$
$2501<\ldots$

- NUTS3 Capital

Figure 2. Jobs accessible within 60 minutes by car. 


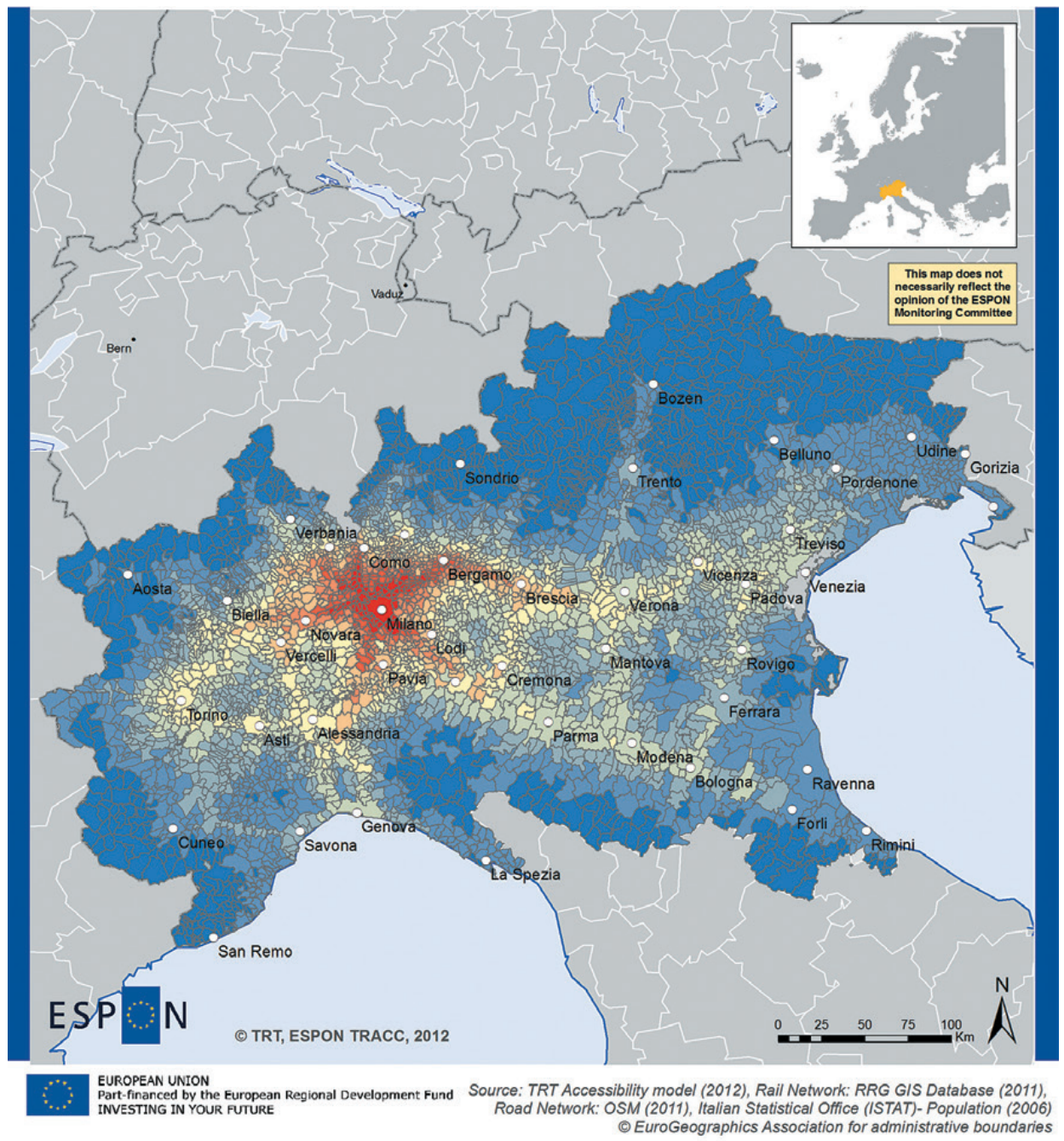

Northern Italy Case Study (2011)

Regional potential accessibility to population by road $(\beta=0.034657)$ (standarised on road average)

$0.0-25.0$

$25.1-50.0$

$50.1-75.0$

$75.1-100.0$

$100.1-125.0$

$125.1-150.0$

$150.1-175.0$

$175.1-200.0$

$2 n \cap 1<$
NUTS3 Capital

\section{0 (population weighted average) $=1703198$}

Minimum: 28411

Maximum: 4390428

Figure 3. Potential accessibility to population by car. 


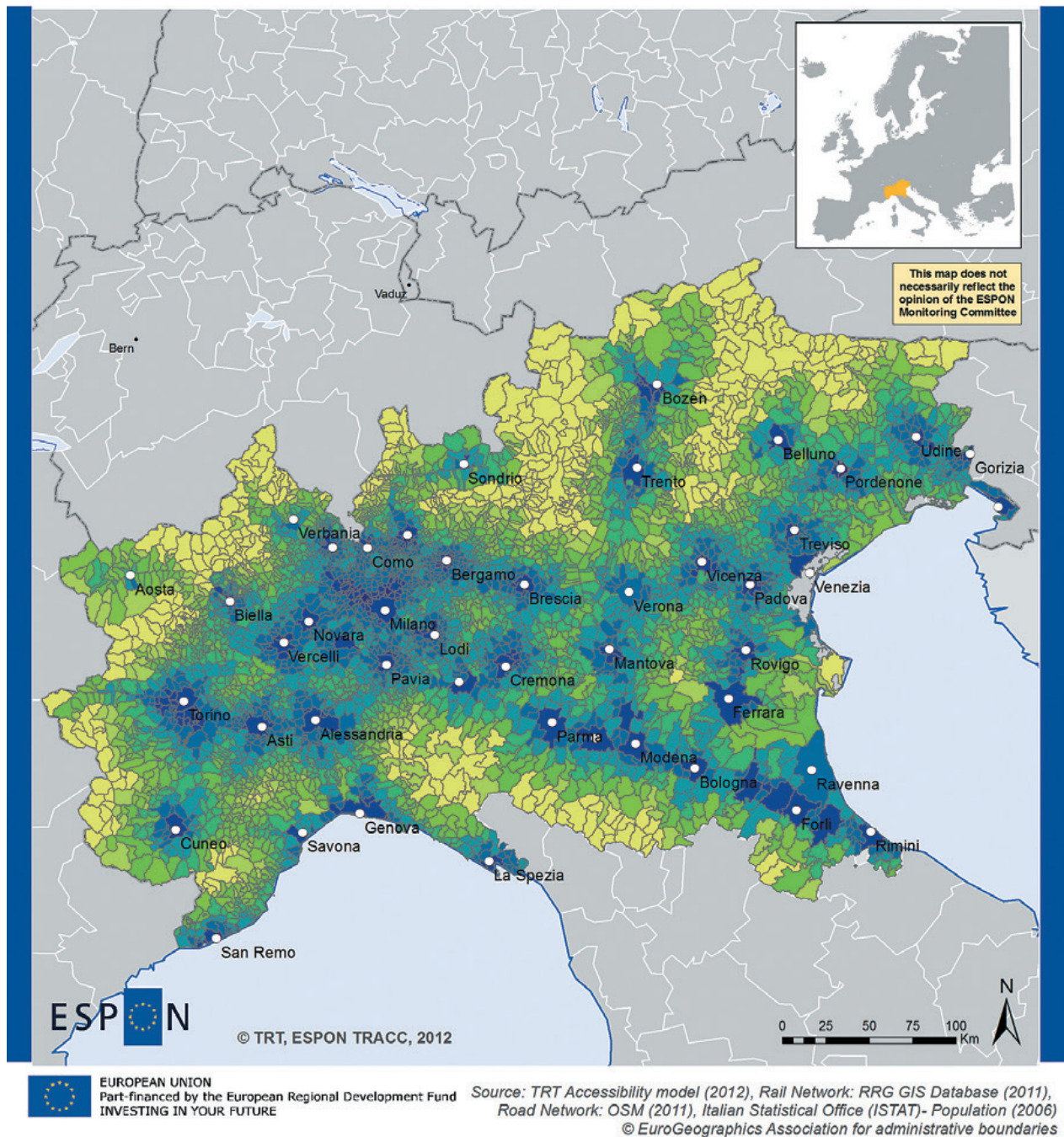

Northern Italy Case Study (2011)

Access to regional centres: Travel time $(\mathrm{min})$ to nearest regional centre by public transport
$0-10$
$11-20$
$21-30$
$31-40$
$41-50$
$51-60$
$61-70$
$71-80$
$81<\ldots$

NUTS3 Capital

Figure 4. Travel time to nearest regional centre by public transport. 


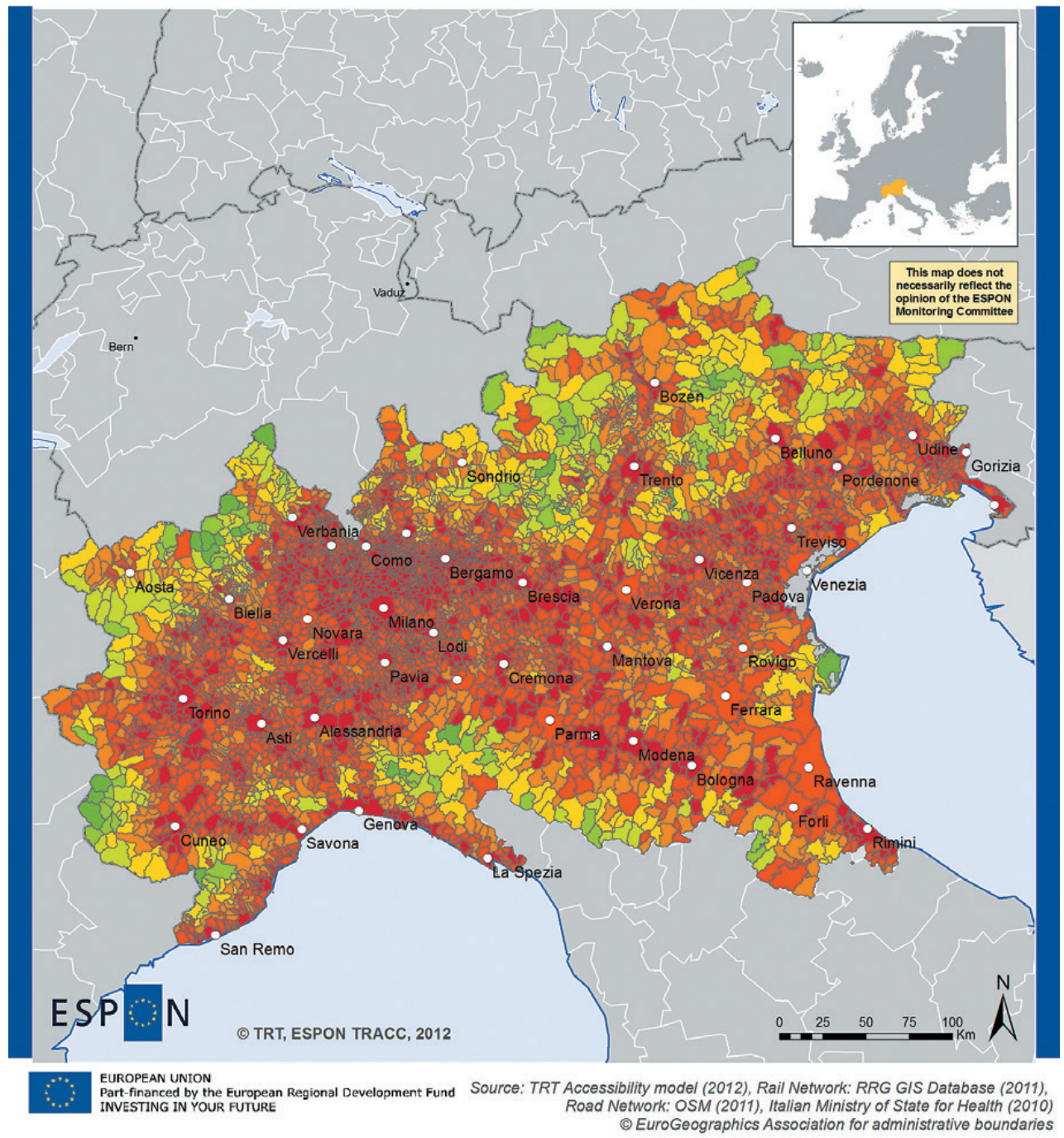

\section{Northern Italy Case Study (2011) \\ Access to health care facilities: Travel time $(\mathrm{min})$ to nearest hospital by road}

\begin{tabular}{|l}
$0-10$ \\
$11-20$ \\
$21-30$ \\
\hline$\square 1-40$ \\
$\square$ \\
$41-50$ \\
$51-60$ \\
$61<\ldots$
\end{tabular}

Figure 5. Travel time to nearest hospital by car. 


\section{Impact of future TEN-T road network developments}

The main impacts expected as a result of the implementation of the TENs on accessibility in the Northern Italy study area have been investigated using the potential accessibility to the population as the reference indicator.

TEN-T projects are based on outline plans of the European Union (European Commission, 2011), (TEN-T Executive Agency, 2012).The major TEN-T projects envisaged in the case study area are rail projects, namely the new connection between Turin and Lyon, including the new Frejus tunnel, and the new Brenner tunnel. These are both large rail projects aimed to significantly increase the capacity of rail transport. In both cases, however, the projects are more relevant for long distance international traffic (especially freight traffic) than for mobility within the Northern Italy region. The completion of high speed rail connections on the west-east axis, from Milan to Trieste - also part of the Lisbon-Kiev corridor - is instead expected to improve rail connections also for regional demand (also providing more capacity for local trains on the current tracks). The same holds for the high speed rail connection between Milan and Genoa, and especially for the upgrades of existing links.

Comparatively, TEN-T road projects are more limited. The main project is probably the "New Romea" crossing Romagna in the south-eastern part of the study area. The project is aimed at alleviating the significant congestion affecting the current state road "Romea", also because of the freight traffic generated by Ravenna and Ferrara ports. Other two significant projects are the "PedemontanaLombarda" and the "PedemontanaVeneta" motorways providing alternative east-west connections for the densely populated areas north of Milan and north of Venice. For many years, the availability of a fast connection to move from the east to the west and vice versa has been the request of local communities as well as businesses.

The overall picture of car potential accessibility has not changed dramatically. As shown in Figure 6, larger accessibility changes are expected in particular in LAU2 zones close to new roads. In the eastern part of the study region, advantages are more widespread even if changes are not that significant. Variations are usually more significant when new infrastructure is built where currently there are no motorways. This is the case in the area on the "New Romea" which, therefore, seems able to provide improvement of travel conditions. However, this is also the case in a couple of peripheral mountainous areas - north-west and south-east of the study region - where less known (at least in Italy) and somewhat smaller projects can be helpful.

Another case for significant improvement of accessibility is where infrastructures already exist but the size of the population involved is large. In these conditions, improvement of the indicator is explained by the number of inhabitants rather than by travel time. This happens for instance in the corridor between Milan and Bergamo as well as the in the north-eastern part of NUTS 2 Veneto.

Changes depicted in the map are relative with respect to the initial accessibility level of each zone. Most of the zones where the improvement occurs are either much less accessible than the average (e.g. mountain areas) or already more accessible than the average (e.g. the corridor between Milano and Bergamo). Therefore, if one looks at the absolute levels of accessibility, the overall pattern in the study region has not changed much. In summary, the modelling exercise suggests that the planned TENs in the Northern Italy area will provide local benefits, but will not change the current accessibility pattern with reference to regional mobility. 


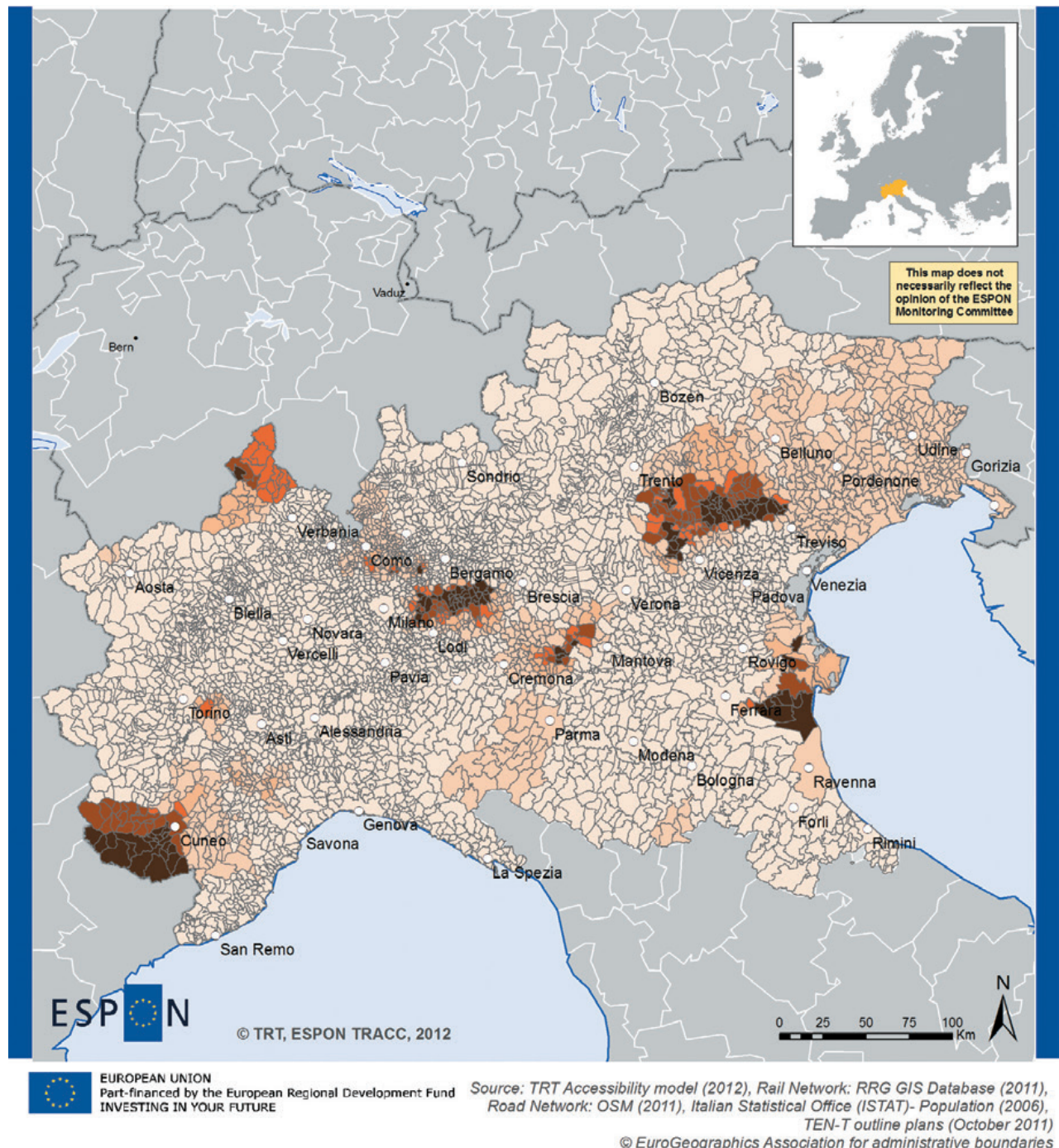

\section{Northern Italy Case Study \\ Future situation after implementation of TEN-T outline plans (2020) \\ Regional potential accessibility to population by road $(\beta=0.034657)$; relative change (\%) (standarised on road average)}
$0.0-5.0$
NUTS3 Capital

$5.1-10.0$

$10.1-15.0$

$15.1-20.0$

$20.1-25.0$

$25.1<\ldots$

Figure 6. Relative increase in potential accessibility to population by car with TEN-T projects. 
The major reason behind this outcome is that the potential accessibility pattern is tightly related to population distribution. Nonetheless, two relevant specifications should be made to this conclusion. Firstly, improved connectivity can induce some relocation of the population and jobs, so that an indirect impact on potential accessibility could emerge in the longer run. Secondly, the analysis carried out under the exercise is focused on potential accessibility to the population of the area, i.e. local or regional passenger demand is covered. If national and international demand for passenger and freight transport was taken into account, the outcome could be different.

\section{Conclusions}

In this chapter, accessibility of the Northern Italy region is analysed by means of four indicators. The overall picture is one of a region with high levels of local accessibility. Two-thirds of the population can reach more than 1 million jobs in less than one hour by car. At the same time, almost $90 \%$ of inhabitants do not need more than 20 minutes to reach the closest hospital and more than half of them can get to the nearest regional centre in 30 minutes or less using public transport (this result is partially conditioned by the definition of a regional centre). Also looking at potential accessibility to the population (by car), results show a relatively even distribution of accessibility at least in the core of the area, with LAU2 well below the average, accounting for only $6 \%$ of the population.

Even as differences in accessibility for the population are generally limited, accessibility of jobs is even less variable in the area. One reason is that in many areas of the study region jobs are more evenly distributed than the population. The second reason is methodological as two different indicators are used. Given the density in the core of the study area, calculating the number of functions available within one hour provides a flatter picture than the indicator which detect whether the function is 15 minutes of 45 minutes away.

Transport infrastructures play some role in explaining the differences in accessibility even though they are not the major driver. Indeed, the most disadvantaged LAU2 zones suffer their peripheral (and often mountainous) condition rather than the lack of roads or transport services. However, in some cases it can be detected that the people who live closer to the main infrastructures do enjoy higher accessibility. For instance, the role of the motorway network can be recognised especially along the corridor from Milan to Brescia passing through Bergamo and along the "via Emilia" from Milan to Bologna. Instead, the accessibility of regional centres is significantly lower than the average not only in peripheral areas, but also in some parts of the study region where rail infrastructure is underdeveloped.

The study region can be split into four main subzones; within the subzones, accessibility is quite homogeneous while between the subzones the accessibility changes significantly. The first subzone is the metropolitan area of Milan and its surroundings. This subzone is significantly at the top of accessibility values thanks to the structure of transport networks (and of transport services) as well as the concentration of activities. The second subzone consists of the subalpine area extending east and west of Milan (from Turin to Venice) and of the corridor from Turin to Rimini (at the south-east corner of the study region). This second subzone, broadly corresponding to the "Padan megalopolis", also displays a high level of accessibility, sometimes even as high as those of the metropolitan area of Milan. The third subzone includes the mountain part of the study area at its northern and southern borders. This subzone generally displays quite poor accessibility, but it is also very sparsely 
populated. Finally, the fourth subzone consists of the remaining zones, which are located in between the other ones and present a medium level of accessibility.

The impact of new infrastructures on potential accessibility to the population is significant only at the local level, whereas the overall pattern in the study region does not change that much. Variations are usually significant if new infrastructure is built where currently there are no motorways or where infrastructures already exist, but the size of the population concerned is so large that even a small benefit in term of travel time allows to reach more inhabitants.

\section{References}

Biosca O., Spiekermann K., Stępniak M., 2013. Transport accessibility at regional scale, EUROPA XXI, vol. 24, pp. 5-17.

EEA, 2006. European Environment Agency, UMZ http://www.eea.europa.eu/data-and-maps/data/ urban-morphological-zones-2006-umz2006-f3v0 [25 September 2013].

ESRI, 2008. Water UTM region, http://sedac.ciesin.columbia.edu/geonetwork/srv/es/metadata. show?id=3452 [25 September 2013].

European Commission, 2011. Decision No 661/2010/EU of the European Parliament and of the Council of 7 July 2010 on Union guidelines for the development of the trans-European transport network. http://eur-lex.europa.eu/JOHtml.do?uri=OJ:L:2010:204:SOM:EN:HTML [25 September 2013].

Fiorello D., Bielanska D., 2013. TRACC Regional Case Study Book, Part B: Northern Italy case study [in:] Spiekermann K., Wegener M., Květoň V., Marada M., Schurmann C., Biosca O., Segui A.U., Antikainen H., Kotavaara O., Rusanen J., Bielańska D., Fiorello D., Komornicki T., Rosik P., Stępniak M., TRACC, Transport Accessibility at Regional/Local Scale and Patterns in Europe, Final Report Volume 3. ESPON, European Union.

ISTAT, 2001. $8^{\text {th }}$ General Census of Industry and Services 22 October 2001 - Workplaces (LAU2). http://dwcis.istat.it/cis/index.htm [25 September 2013].

ISTAT, 2006. Territorial Indicators - Population (LAU2). http://sitis.istat.it/sitis/html/ [25 September 2013].

Italian Ministry of Health, 2010. Basic Health Care Data by region. http://www.salute.gov.it/portale/ documentazione/p6_2_8_4_1.jsp?lingua=italiano\&id=3 [25 September 2013].

NOAA, 2009. National Oceanic and Atmospheric Administration. http://www.ngdc.noaa.gov/mgg/ global/global.html [25 September 2013].

Open Street Map, 2011. Road network/ Hospitals layer. http://download.geofabrik.de/ [25 September 2013].

RRG GIS Database, 2011. Rail network layer with Thomas Cook and Italian timetables. http://www. brrg.de/database.php [25 September 2013].

TEN-T Executive Agency, 2012. TEN-T Projects by Country, Italy. http://tentea.ec.europa.eu/en/tent_projects/ten-t_projects_by_country/italy.htm [25 September 2013].

Turri E., 2004. La megalopoli Padana. Venezia: Marsilio.

TRENITALIA, 2011. Regional train tariffs and high-speed services. http://www.trenitalia.com/ cms/v/index.jsp?vgnextoid=1b97fe9cd30e7310VgnVCM1000008916f90aRCRD [25 September 2013]. 
Spiekermann K., Wegener M., Květoň V., Marada M., Schurmann C., Biosca O., Segui A.U., Antikainen H., Kotavaara O., Rusanen J., Bielańska D., Fiorello D., Komornicki T., Rosik P., 2011. TRACC, Transport Accessibility at Regional/Local Scale and Patterns in Europe. Interim Report. ESPON, European Union http://www.espon.eu/export/sites/default/Documents/Projects/ AppliedResearch/TRACC/TRACC_Interim_Report_210211.pdf [25 September 2013].

Spiekermann K., Wegener M., Květoň V., Marada M., Schurmann C., Biosca O., Segui A.U., Antikainen H., Kotavaara O., Rusanen J., Bielańska D., Fiorello D., Komornicki T., Rosik P., Stępniak M., 2013. TRACC, Transport Accessibility at Regional/Local Scale and Patterns in Europe. Final Report. ESPON, European Union. 